\title{
Balloon-assisted microcatheter navigation for AVM embolization: technical note
}

\author{
George A. C. Mendes, MD, Eduardo Pedrolo Silveira, MD, Suzana Saleme, MD, \\ Christina losif, MD, MSc, PhD, Sanita Ponomarjova, MD, François Caire, MD, PhD, and \\ Charbel Mounayer, MD, PhD
}

\begin{abstract}
Department of Interventional Neuroradiology, Hôpital Dupuytren, Centre Regional Hospitalier Universitaire de Limoges, Limoges, France
\end{abstract}

\begin{abstract}
Recurrent feeders may preclude a successful arterial catheterization of arteriovenous malformations (AVMs). In this paper, the authors report their experience with the use of a compliant balloon to assist the microcatheter navigation in AVMs supplied by feeders with recurrent configuration.
\end{abstract}

Eight patients with AVMs supplied by recurrent feeders had unsuccessful microcatheter navigation after multiple attempts to catheterize the pedicle. A compliant balloon was inflated in the parent artery immediately after the origin of the feeder. The microcatheter was then advanced over the wire while the balloon provided support for the navigation. Distal access close to the nidus was achieved in all cases. Anatomical cure was documented in $75 \%$ cases. There were no arterial perforations or thromboembolic events.

The described technique is a straightforward method for providing support to microcatheter navigation in certain cases of cerebral AVMs supplied by recurrent arterial feeders. This simple yet effective maneuver may enhance outcomes of AVM embolization by eliminating the need for excessive attempts of catheterization.

http://thejns.org/doi/abs/10.3171/2014.10.JNS141359

KEY WORDS cerebral arteriovenous malformations; recurrent arterial feeders; compliant balloon; microcatheter navigation; interventional neurosurgery

$\mathrm{E}$ NDOVASCULAR management of brain arteriovenous malformations (AVMs) has been revolutionized since the introduction of Onyx (Covidien Neurovascular) liquid embolic agent ${ }^{8,11,16}$ Contemporary technology has afforded better catheter flexibility, facilitating a closer approach to the nidus. ${ }^{8}$ However, unfavorable anatomical configuration of the feeders may preclude a successful approach to the nidus. Excessive attempts to gain distal access may increase the risk of hemorrhagic complications ${ }^{2}$ and lead to unsuccessful endovascular management.

First proposed by Moret et al. ${ }^{10}$ in the 1990s for assisting aneurysm embolizations, nondetachable balloons have acquired broad application in neurointerventional procedures. ${ }^{6,14}$ As in microsurgery, the temporary arrest of the blood flow with a balloon is well tolerated, particularly when performed for a short time ${ }^{13,18}$ Even though much has been written about the multipurpose use of balloons in neurointerventional procedures, $, 3,6,10,14$ no report has addressed the use of a nondetachable balloon to support microcatheter navigation in AVM embolizations.

In this paper, we describe the technical aspects of balloon-assisted microcatheter navigation for treatment of cerebral AVMs supplied by recurrent and/or excessively angulated feeding vessels. Although the use of a balloon to assist microcatheter navigation was reported elsewhere ${ }^{19}$ for treating dural arteriovenous fistulas, this is the first series that demonstrates the feasibility and performance of balloon-assisted microcatheter navigation for approaching cerebral AVMs. Over the last 6 years, this maneuver has been successfully used by the senior author (C.M.), and

ABBREVIATIONS $\mathrm{ACA}=$ anterior cerebral artery; $\mathrm{AVM}=$ arteriovenous malformation; $\mathrm{DSA}=$ digital subtraction angiogram; $\mathrm{ICA}=$ internal carotid artery; $\mathrm{MCA}=$ middle cerebral artery.

SUBMITTED June 25, 2014. ACCEPTED October 20, 2014.

INCLUDE WHEN CITING Published online April 17, 2015; DOI: 10.3171/2014.10.JNS141359.

DISCLOSURE The authors report no conflict of interest concerning the materials or methods used in this study or the findings specified in this paper. 
this report is intended to present this technique to the neurosurgical community. Operative nuances are discussed by presenting illustrative cases.

\section{Methods}

The study protocol was approved by the institutional review board at our institution, and informed consent was obtained from each patient. A retrospective review of our prospectively collected cerebrovascular database was performed for patients with AVMs who underwent embolization between January 2008 and January 2014. A total of 100 AVMs were treated, and we identified 8 cases in which the balloon-assisted microcatheter navigation was required, given the unfavorable anatomical configuration of the feeders. Endovascular management was performed on an individual basis, and the general indications were ruptured presentation and unruptured AVMs with augmented likelihood for bleeding, including intranidal aneurysms, high flow shunts, and venous stenosis. Anatomical cure was defined as total exclusion of the AVM. Follow-up angiograms were systematically performed 6 months after the anatomical exclusion of the AVM.

\section{Description of Technique}

The patient is placed under general endotracheal anesthesia with full heparinization and proper neurological monitoring. Bifemoral arterial access is used. All procedures were performed with a biplane angiography unit (Philips Allura, Philips Medical Systems). Two 6-F guide catheters (Envoy, Codman) are placed at different levels of the cervical internal carotid artery (ICA). A flow-dependent microcatheter (Marathon 1.3-F, eV3/Covidien, or Magic 1.2-F, Balt) is advanced over a microwire (Mirage, 0.008-inch diameter, eV3/Covidien, into the middle cerebral artery (MCA) or anterior cerebral artery (ACA) and directed toward the targeted feeder. A remodeling balloon (Scepter C, MicroVention, or HyperGlide, Covidien) is positioned in the parent artery immediately after the origin of the intended branch. The balloon is then inflated under road-mapping visualization of the arteries to avoid balloon overinflation and arterial rupture. The microcatheter is advanced distally into the recurrent branch as close as possible to the nidus. After achieving a proximal approach to the nidus, the microwire is removed, and then the balloon is deflated. The maximum inflation time is between 1 and 3 minutes. The balloon is kept deflated, and superselective injection is performed through the microcatheter. The maneuver may be repeated if microcatheter repositioning is required.

\section{Results}

The patients demographic and clinical characteristics, as well as the type of balloon used in each case, are presented in Table 1. The patients' mean age at the time of treatment was 29.8 years (range $12-55$ years), and there were equal numbers of male and female patients. The most common presentation was hemorrhage $(n=6,75 \%)$, and $62 \%$ of AVMs were located superficially. The mean nidus size was $4.2 \mathrm{~cm}$ (range 2.8-6 cm). In 6 cases (75\%), the AVMs were supplied by lenticulostriate arteries and the balloon was inflated in the MCA. The Scepter C balloon was used in 5 cases $(62.5 \%)$. A successful approach to the nidus was documented in all procedures. Anatomical exclusion was achieved in 6 cases (75\%). There was no vessel perforation or ischemic event. No neurological deficit was associated with the technique. Two patients with residual AVMs were referred to stereotactic radiosurgery for additional treatment.

\section{Illustrative Cases}

\section{Case 1}

A 26-year-old woman presented with motor seizures. Brain MRI revealed an AVM located in the left frontal operculum, extending until the head of the caudate nucleus with superficial venous drainage (Fig. 1A). A digital subtraction angiogram revealed an AVM supplied by lenticulostriate and prerolandic arteries (Fig. 1B and C). In initial treatment session was scheduled to exclude the deep supply. A microcatheter (Marathon) was advanced over a wire (Mirage 0.008) into a lenticulostriate feeder (Fig. 1D). After multiple unsuccessful attempts to catheterize the feeder, a compliant balloon (Scepter C, $4 \times 20 \mathrm{~mm}$ ) was navigated into the left MCA and positioned immediately beyond the origin of the lenticulostriate arteries (Fig. 1E). The balloon was then inflated, and the microcatheter was advanced over the microwire with gentle forward pressure until close to the nidus. The microwire was removed and the balloon was deflated. Fluoroscopy confirmed stability of the microcatheter (Fig. 1F), and embolization was then

TABLE 1. Demographic and clinical characteristics of the 8 patients who were treated by balloon-assisted microcatheter navigation and type of balloon used

\begin{tabular}{ccccccccc}
\hline $\begin{array}{c}\text { Case } \\
\text { No. }\end{array}$ & $\begin{array}{c}\text { Age }(\mathrm{yrs}), \\
\text { Sex }\end{array}$ & Presentation & AVM Size $(\mathrm{cm})$ & AVM Location & Balloon & Arterial Feeder & Parent Artery & Outcome \\
\hline 1 & $55, \mathrm{~F}$ & Ruptured & 2.8 & Basal ganglia & Scepter C & Lenticulostriate & MCA & Cure \\
\hline 2 & $14, \mathrm{~F}$ & Ruptured & 3.0 & Temporal & HyperGlide & Lenticulostriate & MCA & Cure \\
\hline 3 & $20, \mathrm{M}$ & Epilepsy & 2.0 & Frontal & HyperGlide & Frontopolar & ACA & Cure \\
\hline 4 & $39, \mathrm{~F}$ & Ruptured & 6.0 & Fronto & Scepter C & Lenticulostriate & MCA & Partial \\
\hline 5 & $31, \mathrm{M}$ & Ruptured & 6.0 & Frontal & HyperGlide & Lenticulostriate & MCA & Cure \\
\hline 6 & $12, \mathrm{M}$ & Ruptured & 5.8 & Frontoinsular & Scepter C & Lenticulostriate & MCA & Partial \\
\hline 7 & $41, \mathrm{M}$ & Ruptured & 5.0 & Frontal & Scepter C & Fronto-orbital & ACA & Cure \\
\hline 8 & $26, \mathrm{~F}$ & Epilepsy & 3.3 & Frontal & Scepter C & Lenticulostriate & MCA & Cure \\
\hline
\end{tabular}



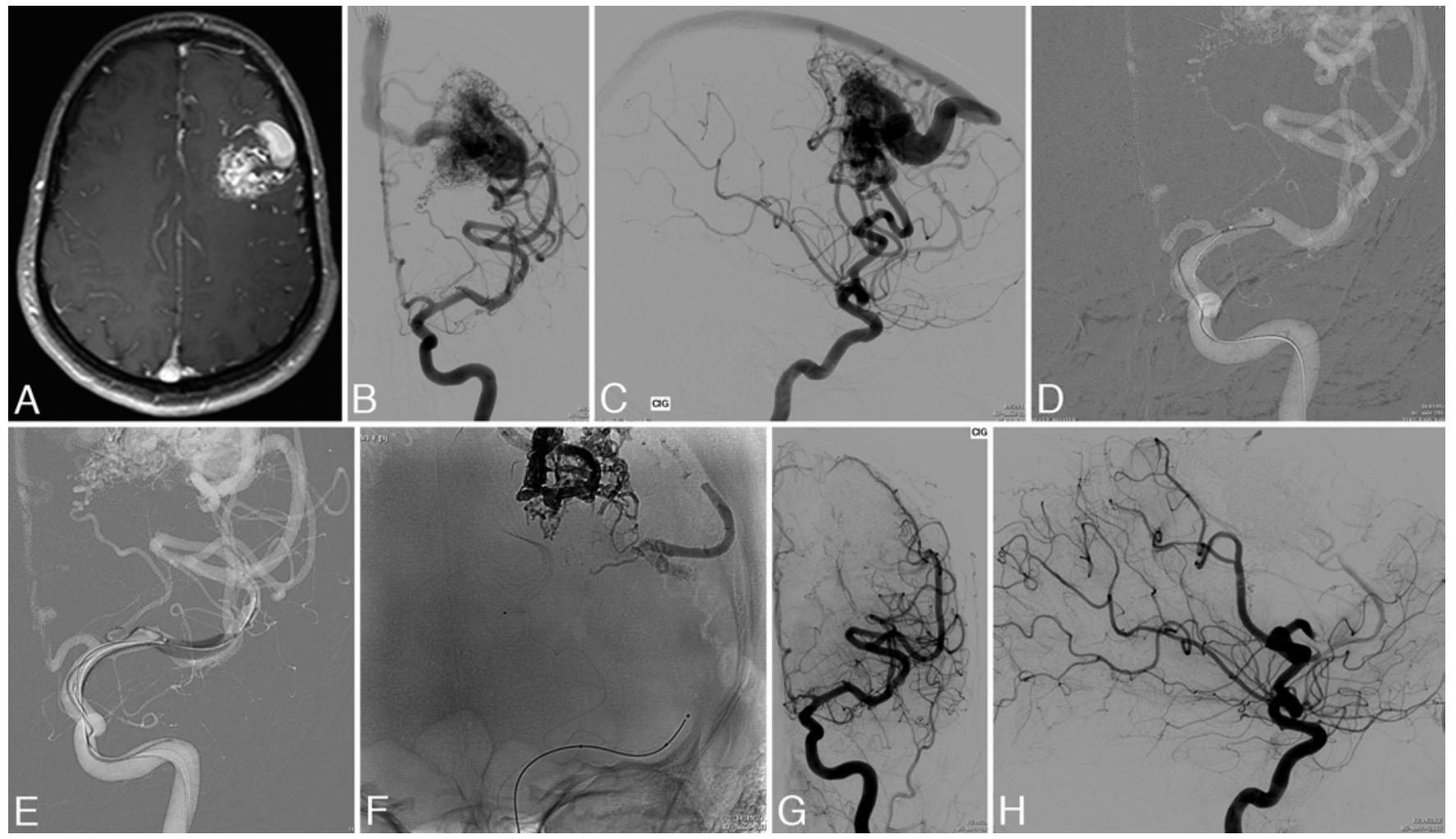

FIG. 1. Case 1. A: Preoperative axial T1-weighted MR image showing an AVM located in the left perirolandic area. B and C: Left selective ICA angiogram, in anteroposterior (B) and lateral (C) projections, revealing an AVM supplied by lenticulostriate and prerolandic arteries, with a nidus measuring $3.3 \mathrm{~cm}$ in the major diameter. D: Intraoperative roadmap image in anteroposterior projection demonstrating the attempt to catheterize a lenticulostriate feeder with recurrent anatomical configuration by using a Marathon microcatheter over a J-shaped 0.008-inch Mirage wire. E: Intraoperative roadmap image in anteroposterior projection showing a Scepter C $4 \times 20-\mathrm{mm}$ balloon inflated in the MCA immediately distal to the origin of the targeted feeding vessel and the microcatheter advanced over the wire through the lenticulostriate artery. F: Native single-shot fluoroscopic image in anteroposterior projection showing the final position of the microcatheter. $\mathbf{G}$ and $\mathbf{H}$ : Anteroposterior- and lateral-projection digital subtraction angiograms ( $\mathrm{G}$ and $\mathrm{H}$, respectively) obtained 6 months after treatment demonstrating complete exclusion of the AVM.

initiated with Onyx (eV3/Covidien). Three months later, the patient underwent a second treatment session via the arterial approach, resulting in total exclusion of the nidus. Follow-up angiography confirmed anatomical cure of the lesion (Fig. 1G and $\mathrm{H}$ ).

\section{Case 2}

An otherwise healthy 41-year-old man presented with a left frontal hematoma 3 months before treatment. MRI revealed an AVM in the left frontal lobe (Fig. 2A). Digital subtraction angiography revealed a large left frontal AVM supplied by branches arising from the anterior cerebral artery (ACA) and MCA with a single cortical draining vein. Given the large size of the nidus and the multiplicity of feeders, the treatment was scheduled in 3 sessions. The first 2 sessions were performed to exclude the superficial supply. The third session was planned to occlude deep portion of the AVM. Selective injection of the left ICA demonstrated supply by branches from the ACA, especially frontopolar and anterior internal frontal arteries with recurrent configuration of the frontopolar artery (Fig. 2B and $\mathrm{C}$ ). Multiple attempts to catheterize the branch failed to achieve access to the AVM. A remodeling balloon (Scepter C, $4 \times 20 \mathrm{~mm}$ ) was inflated in the second segment of the ACA immediately distal to the origin of the frontopolar artery, and the microcatheter (Marathon 1.5F) was advanced over a guidewire (Mirage 0.008) into the frontopolar artery as close as possible to the nidus (Fig. 2D). The wire was removed and the balloon was deflated. Fluoroscopy confirmed stability of the microcatheter (Fig. $2 \mathrm{E}$ ), and embolization was performed with Onyx. Followup angiography confirmed anatomical cure of the lesion (Fig. 2F and G).

\section{Discussion}

Recent advances in endovascular techniques have led to increasing rates of anatomical cure of AVMs. ${ }^{1,5,9,11,16} \mathrm{Fa}-$ miliarization of practitioners with the properties of Onyx and contemporary evolution of endovascular technology have afforded safety for prolonged injection time of liquid embolics. ${ }^{1,8}$ Nevertheless, for accomplishing a successful AVM embolization, the close approach to the nidus remains the major determinant and must be pursued..$^{11}$ It allows the embolic agent to diffuse into the vascular apparatus of the shunt, sparing normal brain supply branches. $1,5,9,11,12,16$

In some instances, especially in the deepest portion of the AVM, recurrent configuration and unfavorable angled loops at the origin of the feeders lead to unstable micro- 

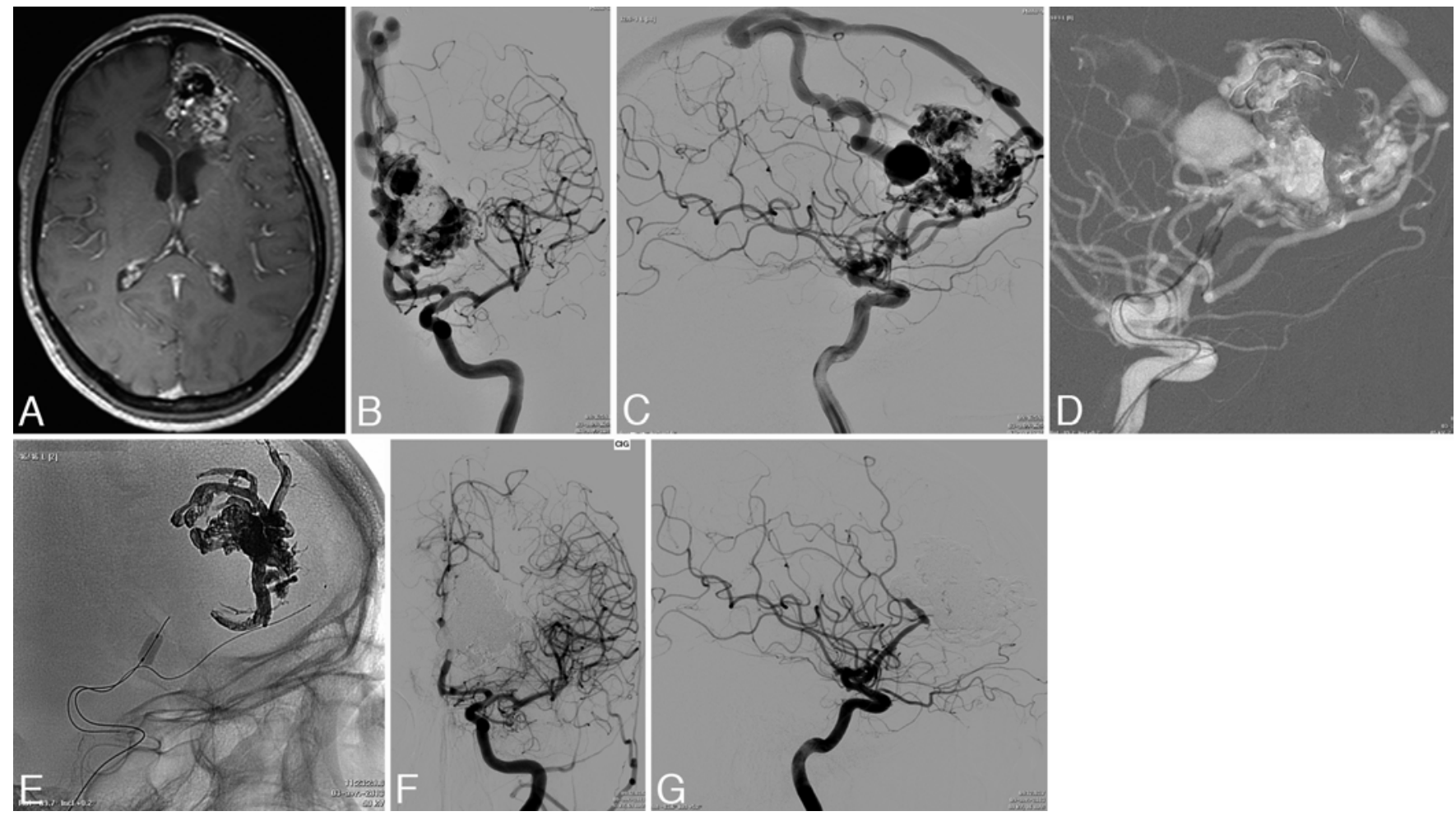

FIG. 2. Case 2. A: Preoperative axial T1-weighted Gd-enhanced MR image showing an AVM deep in the left frontal lobe. B and C: Left selective ICA angiogram, in anteroposterior $(B)$ and lateral $(C)$ projections, revealing an AVM supplied by branches arising from the ACA and MCA with single cortical drainage. D: Road-mapping image in lateral projection demonstrating the disposition of a Scepter $\mathrm{C}$ balloon inflated in the ACA immediately distal to the origin of the frontopolar artery. A Marathon microcatheter was advanced over a 0.008 -inch Mirage guidewire as close as possible to the nidus. E: Native single-shot fluoroscopic image in lateral projection demonstrating the final position of the microcatheter. $\mathbf{F}$ and $\mathbf{G}$ : Anteroposterior- and lateral-projection digital subtraction angiograms ( $F$ and $G$, respectively) obtained 6 months after treatment demonstrating complete exclusion of the AVM.

catheter navigation.7, ${ }^{7,15}$ Attempts to gain distal access result in prolapse of the system into the parent vessel. ${ }^{19}$ The struggling microcatheter navigation usually requires multiple attempts and excessive wire exchanges, leading to distal wire perforation in more than $3 \%$ of cases $^{2}$ and death in up to $4.6 \%$ of patients. ${ }^{4}$ Consequently, AVMs with such angioarchitecture are frequently managed with embolization of the superficial feeders, with the patients being subsequently referred to stereotactic radiosurgery for treatment of the deep supply. ${ }^{15,17}$

Compliant balloons have joined routine practice in neurointerventional procedures. Several applications have been proposed, mostly involving aneurysm treatment. ${ }^{3,10,14}$ Proponents emphasize safety and multipurpose use, which enhance endovascular results..$^{3,6,10}$ Zhao et al. ${ }^{19}$ reported a series in which they used a compliant balloon in the ICA to gain distal access of the microcatheter in a recurrent configuration of the ophthalmic artery during embolization of dural arteriovenous fistulas.

None of the previous publications have demonstrated the feasibility of balloon-assisted microcatheter navigation beyond the ICA bifurcation and focused on cerebral AVMs. This technique is relatively straightforward and helpful in certain surgical instances, especially for AVMs supplied by perforating branches. Typically, these arteries are associated with demanding navigation, given their tortuous trajectory, tiny caliber, and recurrent origin. Cur- rently, we use a Scepter $\mathrm{C}$ balloon for this technique; this is a double-lumen compliant balloon compatible with 0.014-inch wire. Given its compatibility with larger microwires, this type of balloon may offer some advantages over 0.010 -inch wire compatible, including better stability and trackability. These balloons were used only for our last 5 cases, however, as they were not available during our initial experience. The balloon wire should be carefully navigated distally to afford further stability to the system (Fig. 1E). Occasionally, this maneuver may straighten the $\mathrm{M}_{1}$ segment and favorably change the angle of feeders, facilitating selective microcatheterization.

In our experience, the use of a compliant balloon for assisting microcatheter navigation was effective and safe. It afforded distal access in all cases, and we did not have any intraoperative thromboembolic complications or vessel perforations. We believe that the balloon provides a buttress within the parent vessel, which enhances torch to the microwire tip and prevents prolapse into the larger caliber vessel. Similarly, the flow redirection toward the target vessel may assist microcatheter navigation. Followup digital subtraction angiography performed 6 months after treatment did not show any changes in the diameter of arteries treated with a balloon.

\section{Conclusions}

The described technique using a compliant balloon to 
assist microcatheter navigation offers a straightforward method to gain vascular access in certain patients with challenging neurovascular anatomical configuration. In our experience, it has allowed expanded application of endovascular therapy in AVMs previously considered unsuitable for the procedure given the unfeasibility of arterial catheterization. This simple yet effective maneuver may enhance outcomes of AVM embolization by eliminating the need for exchange maneuvers or excessive catheterization attempts.

\section{References}

1. Abud DG, Riva R, Nakiri GS, Padovani F, Khawaldeh M, Mounayer C: Treatment of brain arteriovenous malformations by double arterial catheterization with simultaneous injection of Onyx: retrospective series of 17 patients. AJNR Am J Neuroradiol 32:152-158, 2011

2. Akpek S, Arat A, Morsi H, Klucznick RP, Strother CM, Mawad ME: Self-expandable stent-assisted coiling of widenecked intracranial aneurysms: a single-center experience. AJNR Am J Neuroradiol 26:1223-1231, 2005

3. Cekirge SH, Yavuz K, Geyik S, Saatci I: HyperForm balloon-assisted endovascular neck bypass technique to perform balloon or stent-assisted treatment of cerebral aneurysms. AJNR Am J Neuroradiol 28:1388-1390, 2007

4. Chapot R, Nordmeyer H, Heddier M, Velasco A, Schooss P, Stauder M, et al: The sheeping technique or how to avoid exchange maneuvers. Neuroradiology 55:989-992, 2013

5. Chapot R, Stracke P, Velasco A, Nordmeyer H, Heddier M, Stauder M, et al: The pressure cooker technique for the treatment of brain AVMs. J Neuroradiol 41:87-91, 2014

6. Chiu AH, Aw G, Wenderoth JD: Double-lumen arterial balloon catheter technique for Onyx embolization of dural arteriovenous fistulas: initial experience. J Neurointerv Surg 6:400-403, 2014

7. Consoli A, Renieri L, Nappini S, Limbucci N, Mangiafico S: Endovascular treatment of deep hemorrhagic brain arteriovenous malformations with transvenous onyx embolization. AJNR Am J Neuroradiol 34:1805-1811, 2013

8. Crowley RW, Ducruet AF, McDougall CG, Albuquerque FC: Endovascular advances for brain arteriovenous malformations. Neurosurgery 74 (Suppl 1):S74-S82, 2014

9. Kessler I, Riva R, Ruggiero M, Manisor M, Al-Khawaldeh M, Mounayer C: Successful transvenous embolization of brain arteriovenous malformations using Onyx in five consecutive patients. Neurosurgery 69:184-193, 2011

10. Moret J, Cognard C, Weill A, Castaings L, Rey A: The "remodelling technique" in the treatment of wide neck intracranial aneurysms. Angiographic results and clinical follow-up in 56 cases. Interv Neuroradiol 3:21-35, 1997

11. Mounayer C, Hammami N, Piotin M, Spelle L, Benndorf G, Kessler I, et al: Nidal embolization of brain arteriovenous malformations using Onyx in 94 patients. AJNR Am J Neuroradiol 28:518-523, 2007

12. Natarajan SK, Ghodke B, Britz GW, Born DE, Sekhar LN: Multimodality treatment of brain arteriovenous malformations with microsurgery after embolization with onyx: single-center experience and technical nuances. Neurosurgery 62:1213-1225, 2008

13. Ogilvy CS, Carter BS, Kaplan S, Rich C, Crowell RM: Temporary vessel occlusion for aneurysm surgery: risk factors for stroke in patients protected by induced hypothermia and hypertension and intravenous mannitol administration. J Neurosurg 84:785-791, 1996

14. Piotin M, Blanc R: Balloons and stents in the endovascular treatment of cerebral aneurysms: vascular anatomy remodeled. Front Neurol 5:41, 2014

15. Potts MB, Young WL, Lawton MT, UCSF Brain AVM Study Project: Deep arteriovenous malformations in the basal ganglia, thalamus, and insula: microsurgical management, techniques, and results. Neurosurgery 73:417-429, 2013

16. Saatci I, Geyik S, Yavuz K, Cekirge HS: Endovascular treatment of brain arteriovenous malformations with prolonged intranidal Onyx injection technique: long-term results in 350 consecutive patients with completed endovascular treatment course. J Neurosurg 115:78-88, 2011

17. Söderman M, Andersson T, Karlsson B, Wallace MC, Edner G: Management of patients with brain arteriovenous malformations. Eur J Radiol 46:195-205, 2003

18. Tanabe J, Ishikawa T, Moroi J, Suzuki A: Preliminary study on safe thresholds for temporary internal carotid artery occlusion in aneurysm surgery based on motor-evoked potential monitoring. Surg Neurol Int 5:47, 2014

19. Zhao WY, Krings T, Yang PF, Liu JM, Xu Y, Li Q, et al: Balloon-assisted superselective microcatheterization for transarterial treatment of cranial dural arteriovenous fistulas: technique and results. Neurosurgery 71 (2 Suppl Operative):ons269-ons273, 2012

\section{Author Contributions}

Conception and design: Mendes, Saleme, Mounayer. Acquisition of data: Mendes, Silveira, Iosif, Ponomarjova, Caire, Mounayer. Analysis and interpretation of data: Mendes, Mounayer. Drafting the article: Mendes, Silveira, Mounayer. Critically revising the article: Mendes, Mounayer. Reviewed submitted version of manuscript: Mendes, Saleme, Caire, Mounayer. Approved the final version of the manuscript on behalf of all authors: Mendes. Statistical analysis: Iosif, Caire. Administrative/technical/material support: Mendes, Saleme, Ponomarjova, Mounayer. Study supervision: Mounayer.

\section{Correspondence}

George A. C. Mendes, Department of Interventional Neuroradiology, University of Limoges, 2 avenue Martin Luther-King, 87042 Limoges Cedex, France.email: george_mendes@icloud.com. 